\title{
Entre a resistência ao avanço do patamar de vergonha e o mal-estar: algumas considerações sobre a cena musical do pagode baiano
}

\author{
Between the resistance against the advance of the shame \\ threshold and the discontentment: some considerations about the \\ pagode baiano's music scene
}

Ledson Chagas ${ }^{1}$

\begin{abstract}
Resumo: Este artigo tem como objetivo apresentar uma reflexão sobre a existência de níveis de vergonha expressos na cena musical do pagode baiano, que se opõem a um patamar de vergonha mais consolidado como "civilizado", mas que estão relacionados, também, a casos de produção de mal-estar. A partir da análise de informações de um agente da produção desta cena, sobre a relação entre diferentes condutas de segmentos de bandas e seus respectivos horizontes de mercado, e da apresentação de dados etnográficos produzidos em trabalho de campo com observação participante em espaços de consumo, busca-se apresentar como a estratificação social em meio às classes populares permeia suas práticas expressivas de patamar de vergonha, que também são fontes de prazer, de produção comercial com diferentes potências de difusão e de mal-estar. $\mathrm{O}$ artigo tem como objetivo secundário apresentar um quadro no qual o pagode baiano compõe um fenômeno
\end{abstract}

\footnotetext{
${ }^{1}$ Mestre em Cultura e Sociedade pelo Programa Multidisciplinar de Pós-Graduação em Cultura e Sociedade da UFBA (2015). Graduado em Comunicação Social/Jornalismo pela UFBA (2011). Este artigo é um desdobramento de minha dissertação de mestrado, tendo a pesquisa contado com uma bolsa CAPES. E-mail: ledsonchagas@gmail.com.
} 
mais amplo a que se sugere denominar como cenas musicais juvenis, erótico-dançantes e periféricas contemporâneas.

Palavras-chave: pagode baiano; patamar de vergonha; fração de classe; mal-estar

Abstract: This article aims to present a reflection on the existence of levels of shame expressed in the pagode baiano's music scene, which oppose a shame threshold more consolidated as "civilized", but also are related to cases of production of discontent. From the analysis of information given by an agent of the production, about the relationship between the manners of different segments of bands and their respective market horizons, and from the presentation of ethnographic data produced in fieldwork with participant observation in consumption sites, it seeks to present how social stratification among the popular classes permeates their practices that are expressive of their shame threshold and also are sources of pleasure, of commercial production with different capacities of diffusion and of discontent. The article has as secondary objective to present a picture in which the pagode baiano composes a broader phenomenon that is suggested here to denominate as contemporary "ghetto" youth eroticdancing music scenes.

Keywords: pagode baiano; shame threshold; class fractions; discontent

\section{Introdução: cenas musicais juvenis, erótico-dançantes e periféricas contemporâneas}

Os diferentes padrões de gosto e suas efetivações nas práticas de produção e de consumo cultural são, parcialmente, elementos estruturados pelas e estruturantes das mais variadas sociedades. As disputas mais ou menos explícitas que, muitas vezes, compõem as relações entre os agentes dessas práticas, ao que parece, ganham em agudeza quando as sociedades são 
acentuadamente marcadas por desigualdade sócio-econômica e por diferença cultural. No campo musical, seja no diálogo platônico em que Sócrates orienta quais harmonias devem ser suprimidas e quais devem permanecer (PLATÃO, 1997, p. 9192), seja nos ataques e tentativas de controle das elites administrativas e religiosas contra, sobretudo, os desdobramentos musicais africanos em nossa história colonial, com fontes tão bem coligidas por Tinhorão (1998; 2008), os registros indicam como a produção/consumo musical, ao unir identitariamente grupos, os opõe a outros.

Contemporaneamente, podemos distinguir, dentro de um contexto mais amplo e complexo formado, também, por oposições entre grupos sociais e práticas musicais, a existência de algumas cenas (STRAW, 2002) e gêneros musicais (JANOTTI JR., 2006) ${ }^{2}$, produzidos e consumidos - tanto em shows ou

${ }^{2}$ A noção de cena musical está sendo utilizada aqui como proposta por Straw (2002): "redes de interconexão social, cultural e econômica" nas quais se desempenham práticas como "comer, beber, dançar e conversar publicamente - (e que) envolvem negociação contínua sobre as relações apropriadas entre conversa e barulho, barulho e música, atenção e distração, movimento humano e as formas físicas que o englobam" (p. 247-249). Em uma outra definição não restrita ao contexto musical, "as esferas circunscritas de sociabilidade, criatividade e conexão que tomam forma em torno de certos tipos de objetos culturais no transcurso da vida social desses objetos" (STRAW apud JANOTTI JR., 2012, p. 9). A grande abrangência dessa noção está indicada por ela poder dar conta tanto de fenômenos de "circulação global da música popular massiva", como o heavy metal, por exemplo, quanto de fenômenos de circulação mais restrita e referências regionalizadas (JANNOTI JR., idem., p. 1), como é o caso de muitas das cenas mencionadas neste artigo. Com base na noção de mediação, proposta por Jesús Martín-Barbero (ver nota de rodapé 7 , deste artigo), assim Janotti Jr. define, por sua vez, o gênero musical: "gramáticas de produção do formato canção que envolvem estratégias produtivas e o sistema de recepção, os modelos e os usos que os 
eventos presenciais quanto através de mídia massiva -, sobretudo, por jovens, em grande proporção em espaços populares e periféricos, e que estão atrelados a intensas polêmicas formuladas com base em interpretações sobre suas características.

No Brasil, foram o gênero e a cena funk carioca que mais ganharam destaque nesse contexto. Entretanto, a América Latina, o Caribe e alguns países na África também produziram seus muitos outros exemplares que se encaixam nesse fenômeno disperso geograficamente, mas com visíveis características semelhantes entre suas diferentes manifestações (o que não implica, contudo, a necessidade de uma abordagem homogeneizadora) e ainda não entendido no que lhe há de integralidade. Se tudo indica que, juntamente com frações do bem mais famoso hip hop norte-americano, o fenômeno integra uma grande parcela da produção cultural contemporânea e massiva dos jovens periféricos do Atlântico Negro, termo proposto por Paul Gilroy (2001), creio ser necessário também aprofundar as comparações entre ele e, por exemplo, as produções mais mainstream e mais underground das classes médias, sobretudo brancas, das Américas. A tarefa, no entanto, não é fácil, e mesmo dentro desse domínio que tento recortar, os trabalhos comparativos ainda são uma exceção (exemplos: RODRIGUES, 2011; SANZ GIRALDO, 2014), abrangendo o pagode baiano e o tecnobrega paraense no caso do primeiro e a champeta cartagenera (Colômbia) e funk carioca no segundo. Ainda no sentido de captar essa integralidade, considero que Rodrigues, mobilizando o referencial teórico de Norbert Elias,

receptores fazem desses modelos através das estratégias de leitura inscritas nos produtos midiáticos. Antes de ser um elemento imanente aos aspectos estritos da música, o gênero estaria presente no texto através de suas condições de produção e reconhecimento" (JANOTTI JR., 2006, p. 7). 
traz importante contribuição ao propor o termo erótico-dançante para se referir às linguagens miméticas que geram, na interação entre pessoas nas festas populares com consumo desses gêneros, um padrão de gratificação psíquica na direção do prazer diversional (2013, p. 6).

Uma outra interseção entre muitas dessas diferentes cenas/gêneros musicais é o tema do machismo, presente também em relação a grande parte da produção cultural marcada pela dominação masculina característica da dimensão patriarcal da maioria das sociedades. Merece destaque, em relação ao fenômeno abordado neste artigo, entretanto, que essa interpretação sobre algumas de suas características não ocorre na mesma medida e da mesma maneira entre: os agentes das instâncias institucionais ${ }^{3}$ e da opinião pública que se manifestaram quanto a isso, os trabalhos acadêmicos que abordaram esse ponto, os detratores em geral destas cenas

3 Ações institucionais contra vários dos gêneros musicais mencionados, associadas tanto ao combate ao machismo quanto a uma antipatia em relação ao que seus agentes consideram ser obsceno, foram uma constante nos últimos 20 anos, como no caso da Lei Antibaixaria, que teve foco no pagode baiano (ver nota de rodapé 13, deste artigo), o do Comité Federal de Radiodifusión, da Argentina, que em 2001 mobilizou-se para impedir a difusão da cumbia villera em TV e rádio (SEMÁN, 2012, p. 154), as ações da Senadora Velda González sobre o reggaeton (e, antes, sobre o underground, seu antecedente), em Porto Rico, 2002 (https://web.archive.org/web/20071221230347/http://news.nacla.org/20 07/12/17/reggaeton-nation/), ou ainda a ação do Jamaica Broadcasting Commission, de banir das rádios nacionais canções com letras de conteúdo sexual explícito, em fevereiro de 2009, com foco maior no dancehall (https://www.theguardian.com/music/2009/feb/24/jamaicabans-sex-violence-airwaves), além de outros casos. Não devemos nos esquecer, entretanto, que fontes como Bakhtin e Tinhorão destacam como as instâncias institucionais há muito impõem sanções a várias manifestações da cultura popular. Acesso: 25/04/2017. 
musicais e, enfim, seus praticantes como um todo (produtores e consumidores) e os não praticantes simpáticos a elas por motivos outros que não exatamente sua inserção neste universo. Essa gradação interpretativa, devo destacar, configura um contexto não só complexo como também problemático, no qual, muitas vezes, um etnocentrismo disciplinador se opõe a uma vivência intensa e, talvez em muitos dos casos, com pouca auto-reflexão.

Da produção acadêmica, Semán e Vila (2007), por exemplo, sem se deterem confortavelmente em sua interpretação das letras da cumbia villera (Argentina) que, para eles, retratam agressivamente as mulheres (p. 4), trazem importante contribuição quando, em abordagem etnográfica, apresentam as gradações de interpretação do público feminino deste gênero sobre as letras das canções ${ }^{4}$, que variam: a) da aceitação cômica em espaços de show complementada por crítica e vergonha fora do contexto lúdico do consumo (p. 3738 ), passando b) por modos seletivos de escuta, que enfatizam o ritmo e os arranjos, em relação às letras (p. 40), até c) a aceitação prazerosa das representações femininas nas letras que, a outras jovens no mesmo público, suscitam, parcialmente, crítica, vergonha ou contradição (p. 43). Sobre o contexto de produção masculina dessas letras, os pesquisadores destacam processos contemporâneos como o de juventude estendida (marcado por fraca inserção dos jovens no mercado de trabalho formal ainda que eles trabalhem - e crescente importância da indústria cultural), além da autonomização da dimensão sexual em relação ao casamento e à reprodução, entre os rapazes e moças

${ }^{4}$ Embora talvez possa causar certa estranheza denominar o tipo de produção musical destes gêneros como canção, ele também se encaixa no formato das "pequenas peças formadas de melodia e letra" (TATIT, 2008, p. 11), no "emprego genérico que modernamente lhe atribuímos" (idem, p. 146). 
das classes populares, em paralelo ao "que ocorre entre as classes médias imbuídas de ideais de liberação sexual", mas particularizado por uma estrutura na qual, "para eles e para elas, ainda quando queiram praticar, a liberdade feminina quanto à relação sexual segue fazendo, das mulheres, putas" (p. 25-26, todas as traduções são minhas).

Outra dimensão de suma importância para a produção e o consumo dos gêneros musicais abordados neste artigo - e que nem sempre recebe a devida atenção nos estudos sobre esses fenômenos - foi destacada por Fontanella (2005), em estudo sobre a cena musical do brega pop recifense, quando o pesquisador observa que, "para a sua correta fruição, a dança deve contar com um corpo indisciplinado: é comum a menção pelos bregueiros (o público do brega pop) de que para dançar o brega se necessita 'não ter vergonha' " (p. 57). Mobilizando as reflexões teóricas de Bakhtin sobre o corpo grotesco, Nietzsche e o dionisíaco, Bourdieu e a estética popular com maior ênfase na função do que na forma (gosto de necessidade) e Elias ${ }^{5}$ sobre a função desempenhada pelo avanço do patamar de vergonha no processo civilizador ocidental, Fontanella busca interpretar as características da sensibilidade popular que dá base, já em ambientação midiático-massiva, à cena do brega pop, bem como a recepção negativa - com corte de classe - que marca a relação das produções dessa cena com seus detratores, destacando que:

Não é incomum a referência ao sexo nas músicas dos mais diversos estilos

\footnotetext{
${ }^{5}$ Norbert Elias tem sido uma referência utilizada em alguns dos estudos destas cenas musicais. Sobre o pagode baiano, além do já citado Rodrigues, também Oliveira, em breve menção (2001, p. 111). Sobre o funk carioca, ver Cecchetto (2004), sobre a excitação através de tensão mimética em brigas em baile funk e Mattos (2006), em interpretação da categoria nativa neurose nos significados e experiências de violência entre jovens funqueiros.
} 
propagados pelas indústrias culturais. Mas o desvio das letras do Brega Pop está em uma citação explícita e sem idealizações, que choca os gostos mais refinados. Norbert Elias menciona como a idéia de civilidade não só tornou repugnante a exposição das funções corporais em público, mas também tornou abominável falar sobre elas ou sobre as associações que elas despertam; quando um indivíduo se comporta com liberdade na referência a essas funções, ou com "falta de vergonha", ele causa embaraço para aqueles que adotam o padrão de polidez (1994: 139140) (FONTANELLA, idem, p. 99).

Um prazer experienciado através da mimetização (em danças e letras) da dimensão sexual, possibilitado por certa recalcitrância (apenas parcialmente consciente e intencional, mas nunca programática - e de “origem" extremamente complexa) quanto a um patamar de vergonha equivalente às condutas mais ou menos (ou seja, circunstancialmente) consideradas como civilizadas, e atravessado por uma assimetria na potência de produção e difusão de representações de gênero (sexual) e das relações entre os gêneros. Essas me parecem ser as linhas gerais de um fenômeno amplo, do qual, neste artigo, me concentro, como em um de seus exemplares, na cena musical do pagode baiano.

Através da análise da relação entre a estrutura empresarial atual do campo de produção deste gênero e as condutas adotadas por distintos segmentos de bandas, captada através de afirmações de um agente da produção (publicadas em entrevista de site jornalístico), e de reflexão sobre material etnográfico que elaborei em trabalho de campo com observação participante em espaços de consumo, neste artigo, busco pensar sobre como um patamar de vergonha (e de embaraço) 
específico entre o grupo social que dinamiza essa cena se impõe, contra um patamar mais "civilizado" que lhe renega e rebaixa, mas, em relação com a estratificação social dentro do mesmo grupo, proporciona fontes de mal-estar. A noção de patamar de vergonha é pensada aqui como utilizada por Norbert Elias (1993; 2011). A noção de mal-estar pertinente ao nosso caso, por sua vez, é bem captada - embora referente a sociedades européias e norte-americanas, em grande medida diferentes da realidade histórica e econômica que nos concerne - no destaque que Bauman dá ao "princípio de prazer" na contemporaneidade (1998, mais sinteticamente, p. 7-11). Por fim, a noção de frações de classes, trabalhada por Bourdieu (2008), foi utilizada aqui, em adaptação, para dar contornos à estratificação em meio às classes populares soteropolitanas, base de consumo e da produção do pagode baiano. Em linhas mais gerais, trata-se de pensar como o patamar de vergonha expresso na cena musical do pagode baiano se opõe, como "resistência", a um patamar (dito) mais civilizado, mas, em meio aos seus próprios matizes, abrange também produção de mal-estar.

\section{Pequena fresta para o conflito no âmbito da produção}

Em linhas gerais, o pagode baiano é um gênero musical midiático-massivo (suas canções, ao longo de sua trajetória, foram difundidas em emissoras de rádio líderes de audiência na cidade de Salvador, como a Piatã FM), configurado em meados dos anos 90 (Século XX), tendo como antecessores imediatos manifestações festivas populares, urbanas, em Salvador (Bahia), e ainda não ou apenas parcialmente comercializadas, dos anos 80: os sambas juninos e os pagodes de mesa, cada um deles, respectivamente, apresentando um tipo de samba (música) específico: o samba corrido/samba duro 
(desdobramento do samba de caboclo do candomblé6) e o samba ou pagode de fundo de quintal (de origem carioca) (LIMA, 2003, p. 117; OLIVEIRA, 2001, p. 55-66; RODRIGUES, 2011, p. 202240). Elementos coreográficos e referentes às letras são registrados como remontando, ao menos, aos anos 40 e 50 (Século XX), em modalidades de dança e de canto do samba de roda, na cidade de Cachoeira (SERRA, 2009, p. 113-135) e no Recôncavo Baiano em geral (RODRIGUES, 2011, p. 205-208). A literatura e a iconografia sobre os desdobramentos de manifestações africanas religiosas e, posteriormente, de lazer, no Brasil, numa linha entre os "batuques", fofa, lundus, fado e samba (TINHORÃO, 2008), já indica, entretanto, elementos que permaneceram nas características e interpretações sobre $o$ pagode baiano, como, respectivamente, por exemplo, a performance coreográfica (e a designação como passo) de "tremer as cadeiras (as ancas, os quadris)" ou o assombro da elite colonial sobre o que lhe parece obsceno nessas performances e cantos ${ }^{7}$.

${ }^{6}$ Ao menos um outro gênero contemporâneo, pertinente a todos os aspectos mencionados na Introdução deste artigo, teve observada sua relação musical com a religião de origem iorubá, a saber, a timba cubana e a música da santería. Ver, nesse sentido, ACOSTA, 1999 e, para análise musicológica e sócio-cultural da timba, LOPEZ CANO, 2005; 2007.

7 Busquei, através da noção de matrizes culturais, proposta por Jesús Martín-Barbero, elaborar uma interpretação sobre a relação entre essa linha histórica de desenvolvimento musical/dançante e o pagode baiano (CHAGAS, 2015a; 2015b). A noção é um dos componentes do mapa das mediações, proposto pelo mesmo autor como ferramenta analítica adequada a produções culturais de difusão midiáticomassivas contemporâneas. Seu uso principal, até este momento, tem sido em estudos sobre a televisão, e uma definição de mediação, nesse contexto, é apresentada por Martín-Barbero: “(d)os lugares dos quais provêm as construções que delimitam e configuram a materialidade social e a expressividade cultural da televisão" (2002, p. 294) e 
Na segunda metade dos anos 90, como subgênero do, mais amplo, gênero musical axé music, o pagode baiano de bandas como Gera Samba/É o Tchan!, Companhia do Pagode e Terra Samba emerge de uma cena musical soteropolitana para uma moda midiática de abrangência nacional (e de circulação, em certa medida, internacional) ${ }^{8}$ que se manteve até o início dos anos 2000. Algumas polêmicas desenroladas nessa ou em relação a essa fase do gênero musical já dão indicação parcial sobre a oposição acima mencionada e que estrutura a interpretação que busco desenvolver neste artigo. Vejamos. Na ocasião da apresentação da banda É $o$ Tchan! no Festival de Montreux, de 1997, a então Secretária de Cultura da cidade do Rio de Janeiro, Helena Severo, se queixou pelo fato de que a dançarina "Carla Perez com seu tchan levou espectadores a invadir o palco, cena jamais presenciada ali". Argumentando contra "quem incentiva, promove e leva ao exterior, muitas vezes com verba oficial, manifestações apelativas, de mau gosto

aprofundada por Lopes, Borelli e Resende (2002), "mediações são dispositivos embutidos em práticas cotidianas e midiáticas", úteis, no plano da reflexão, para "desvendar as articulações contidas, ao mesmo tempo, na narrativa da telenovela, no cotidiano e na narrativa que os receptores dela fazem" (p. 381). No campo musical, entretanto, o mapa das mediações também vem sendo bastante utilizado (ex: LEME, 2003) e, ao meu ver, a vantagem analítica desta ferramenta é o holismo com que tenta capturar as relações entre as matrizes culturais, as competências de recepção, as lógicas de produção e os formatos industriais nos produtos e processos de comunicação de massa.

${ }^{8}$ Apenas no exterior (México, Argentina, Suíça, França, Alemanha e Holanda), o grupo É o Tchan! vendeu 1,3 milhões de discos, em 1997 (LEME, op. cit., p. 105-106). Parte desse período de circulação nacional do pagode é marcado, como aponta Vicente, pelo fato de que a indústria fonográfica nacional, "favorecida pela conjuntura de relativa estabilidade dos primeiros anos do Plano Real (...) viveu, entre 1996 e 1999, os melhores momentos de sua história, alcançando a posição de sexto mercado mundial" (VICENTE, 2008, p. 106). 
e degradantes para o Brasil e, sobretudo, para as brasileiras", Severo destaca que o motivo da "invasão" não se deu "pelos acordes, arranjos ou performance musical dos brasileiros", mas sim, pelo "rebolado primal" da loira baiana [grifo meu] ${ }^{9}$. Em documentário sobre a história do funk carioca, por sua vez, o produtor cultural Thelles Henrique atribui, como contexto de origem das "letras com apelo sexual" neste gênero musical carioca, o fato de que, nos anos 90, quando muitos dos produtores e consumidores de funk eram ainda crianças, o grande sucesso "da mídia" era algo "nada menos agressivo do que [e, em tom de indignação, cantarola]: 'vai ralando na boquinha da garrafa, vai descendo na boquinha da garrafa', e uma mulher seminua se esfregando no gargalo de uma garrafa de cerveja, e isso o maior sucesso!" [grifo meu ${ }^{10}$.

A alusão ao aspecto interpretado e sentido como "primitivo" na performance da dançarina de pagode e o teor de repugnância expresso na entonação e escolha do verbo (se) esfregar, qualificado ainda como agressivo, no segundo caso, exemplificam "o desagrado ou a ansiedade que surgem quando outra pessoa ameaça ignorar, ou ignora, proibições da sociedade representadas pelo próprio superego da pessoa" (ELIAS, 1993, p. 245), ou seja, é o embaraço, "contrapartida inseparável da vergonha" (idem), o que se pode localizar na fala desses dois agentes do campo Cultural. Na medida em que penetramos na descrição do gênero e da cena musical do pagode baiano, entretanto, podemos observar de que maneira a vergonha exerce um efeito específico também entre seus agentes (na produção e no consumo).

${ }^{9}$ Helena Severo, "O país precisa perder o rebolado", Veja, no 1504, p. 19, 16 de Julho de 1997.

${ }^{10}$ Documentário Sou Feia Mas Tô na Moda (Denise Garcia, 2005). O produtor cultural faz menção à canção $\mathrm{Na}$ Boquinha da Garrafa, composição de Willys Batista de Araujo e Eleonor Sacramento Dos Santos, gravada pelo grupo Companhia do Pagode. 
A partir do início dos anos 2000, a moda nacional refluiu e o pagode baiano, aos poucos, foi se restringindo novamente a uma cena musical local, dinamizada pelos shows e eventos constantes em Salvador, recorrentes em todo o estado (Bahia) e, em menor medida, realizados em outros estados. Essa modificação na circulação integra um complexo processo, que contribuiu bastante para a modificação de características do gênero musical, e que tem como alguns de seus eixos: crise na indústria fonográfica; ascensão midiática de outros gêneros musicais dançantes (como o funk carioca); incremento do mercado informal denominado "pirataria" e da internet (blogs, sites e redes sociais) como lócus cada vez mais central à circulação da produção - aparentemente, sem regulações ou com "regulações próprias", em relação às das emissoras de rádio e $\mathrm{TV}$-; e mudanças nas redes de sociabilidade desenvolvidas em Salvador e na Bahia, cada vez mais marcadas pelo aumento da violência urbana ${ }^{11}$.

O surgimento, no pagode baiano, de duas novas vertentes, uma (pagofunk) mais direta no uso de "tabuísmos", com aumento de representações consideradas machistas, por diversos agentes, sobre as mulheres, e outra (groove arrastado e desdobramentos), cujas letras "refletem, reagem e elaboram essa experiência de violência pervasiva" (PINHO, 2014, s/p.) que se fortaleceu na cidade, dão uma indicação particular sobre a dinamicidade característica de todo gênero musical (o que pode influir, inclusive, na reconfiguração da distribuição social de seu público) e integram um contexto agudamente expresso nos trechos da entrevista a seguir, que, apesar de longos, sintetizam também a problemática que tento capturar pela oposição entre resistência, não necessariamente consciente nem

\footnotetext{
${ }^{11}$ Não há como aprofundar a apresentação dos eixos desse processo neste artigo. Para mais detalhes, conferir minha dissertação de mestrado (CHAGAS, 2015b).
} 
programática, ao avanço do patamar de vergonha e certos malestares mais ou menos ligados a ela. Respondendo pergunta sobre o que mudou no pagode baiano entre 2002 (quando ele ingressou na banda Pagod'art) e então (2014) e sobre como ele percebe a relação entre artistas e público do pagode e da axé music (gênero musical com mais produtores e maior fatia de público na classe média, em relação ao pagode), assim o cantor Flavinho pondera:

No início, da minha parte, eu achei que tinha uma resistência dos dois lados [entre artistas e público de pagode e de axé]. Mas também eu não sabia como era, e hoje eu vejo. Uma banda que se cuida, se prepara para estar bem com esses dois lados. Uma banda que começa hoje e não se cuida, é difícil ficar de frente com Ivete Sangalo. Tudo é o começo. No início, você não tem para onde correr, mas chega a hora que você está em um patamar que precisa se cuidar. Pensar "olha, já aprendi isso aqui, não posso ficar mais daquela forma", e você vai aprendendo. No começo foi assim, mas depois de um tempo com o Pagodart eu fui aprendendo e comecei a me dar bem com todos. Eles começaram a ver o meu potencial. A forma que eu chegava nos lugares, que eu me expressava com eles, que eu me expressava nos shows, e começou a rolar melhor. Até no começo, eu tinha danças que eram mais obscenas, mas com o tempo você vê e pensa "isso aqui eu fiz feio". Comecei a olhar os meus vídeos para avaliar. Então você tem que tentar ser educado. Há resistência [contra o pagode]? Há. Mas pelas [por causa das] pessoas que não 
tentam se educar no lugar em que chegam. Espero que a galera que está chegando procure se educar para continuar todo mundo unido, até porque eu não quero ninguém mal-educado na minha casa. Quem vai querer? (...) É o Tchan, Terrasamba, todo mundo que vinha de fora, vinha para ver. Foi para o mundo todo. Eu falo desses caras, que são os pioneiros, para a galera nova entender e pensar "eu quero me espelhar nesses caras porque não quero só tocar em Salvador". Porque tem muita gente que quer ficar só em Salvador. Acha bonito tocar só aqui, arrumar uma namoradinha aqui, a menina achar lindo, gostosão, bonitona... E eu digo "rapaz, vocês têm que descobrir o mundo". Descobrir o mundo deixa o caminho bom para quem está crescendo, que vai querer fazer o mesmo caminho que vocês. Se eles vierem nessa linha que eu procuro fazer, o pagode vai crescer mais ainda e vai sair dessa fase que não está legal não, porque para tocar fora, estamos numa dificuldade imensa. (Os grifos em itálico e entre colchetes são meus $)^{12}$

A resposta do cantor tem como contexto uma série de episódios ${ }^{13}$ que contribuíram para dois processos conjugados:

12

em:

http://www.bahianoticias.com.br/holofote/entrevista/215-o-pagodartagora-e-meu-uma-nova-direcao-diz-flavinho-sobre-retorno.html. Acesso: 25/04/2017.

13 Amplamente divulgados pela mídia baiana e nacional, sinteticamente, esses acontecimentos são: $\mathrm{O}$ caso da professora infantil Jaqueline Carvalho dançando o Todo Enfiado, em 2009; o caso do estupro cometido por integrantes da banda New Hit contra fãs 
fortalecimento de uma imagem negativa do pagode baiano entre amplos setores da sociedade, desde no que talvez seja seu epicentro, as classes médias e altas, até, parcialmente, também nas classes populares; e fortalecimento também do uso da tematização do sexo feita pelas bandas, em letras e danças (e as diferentes maneiras de representá-lo, de modo mais explícito ou mais implícito, mais "visceral" ou mais "romantizado", etc.), como o principal critério de atribuição de qualidade (ou da falta dela) às bandas e suas produções - embora seja um critério em disputa, não seguido nem legitimado igualmente por todas as bandas e frações do público.

Sem que se possa esmiuçar esses dois processos a fundo neste artigo, o que mais interessa aqui, entretanto, é destacar como, na fala do cantor, sua dança sexualizada (de grande importância à contribuição que ele deu a sua banda, o Pagod'art), qualificada pelo mesmo como obscena, tal qual muitas das danças de matriz africana foram adjetivadas por cronistas colonizadores, é percebida por ele mesmo como um empecilho à conquista de mercado em pé de igualdade com as atrações da axé music - gênero que, como já observado, consolidou mais público nas classes médias do que o pagode. A dança obscena é colocada como um dos exemplos de práticas "feias" que, por algum motivo, na fala do cantor, marcam o

menores de idade (o ocorrido foi em 2010; em 2015, foram sentenciados, mas membros da banda continuam soltos); o projeto Anti-baixaria, proposto pela deputada Luiza Maia, discutido a partir de 2011 e aprovado, como Lei, em 2012; além de alguns episódios de disparos de tiros durante shows de pagode e o aumento da ocorrência de brigas nos mesmos, o que tem sido uma das grandes fontes de malestar na cena, já há alguns anos (neste artigo, entretanto, me concentro nas questões de sexualidade). É possível que desavenças entre artistas de pagode baiano e de axé music tenham contribuído também como contexto às afirmações dadas na entrevista, como a que ocorreu entre o cantor Igor Kannário e a cantora Daniela Mercury, em 2012. 
início de carreira das bandas. Por que ocorre dessa maneira? Para angariar atenção - e público - através de performances mais impactantes? Ou por que a expressão da dimensão da corporeidade de seus integrantes, que vem a ser plasmada nas danças, ainda não foi depurada pelo processo de educação necessário a quem quer alcançar públicos mais amplos e diversificados? ${ }^{14}$ Podendo ser pelos dois motivos, o domínio dos limites entre o sensual, o divertido e o habilidoso, por um lado, e o obsceno e o vulgar, por outro, é um requisito de suma importância para a manutenção e, sobretudo, para o incremento dos empreendimentos comerciais que as bandas também são.

Um dos pontos de destaque na fala do cantor traz indicativo de como a oposição que propus se expressa como conflito no âmbito da produção, quando ele se refere a dois horizontes possíveis às bandas: "ficar só em Salvador" ou "descobrir o mundo". Desde que houve a minimização da circulação massiva do pagode baiano pelo território e pela mídia nacional, e acentuou-se sua restrição à cena local soteropolitana, fortaleceu-se também uma estrutura empresarial na qual, de um lado, as bandas com contrato com produtoras mais consolidadas no ramo do entretenimento local minimizavam elementos polêmicos (dos âmbitos sexuais e agressivos/violentos) em suas produções, ao passo que, por sua vez, as bandas mais recentes, contratadas por produtoras de menor capital e menos "tradicionais" no ramo, e com difusão de suas canções ocorrendo mais por blogs e sites do que por emissoras de rádio, foram investindo cada vez mais nos pontos mencionados como polêmicos (CHAGAS, 2015b, p. 86 e 92-93). Se tomarmos as palavras de Norbert Elias sobre a diferença de conduta entre indivíduos ligados por cadeias de ação mais curtas ou mais longas (respectivamente, características de

\footnotetext{
${ }^{14}$ Esse mesmo processo de depuração encontra na linguagem popular um alvo ainda mais prioritário do que a dança.
} 
sociedades com menor ou maior divisão de funções) (ELIAS, 1993, p. 198), podemos interpretar o quadro acima descrito sobre as bandas a partir de que:

Quanto mais apertada se torna a teia de interdependências em que o indivíduo está emaranhado, com o aumento da divisão de funções, maiores são os espaços sociais por onde se estende essa rede, integrando-se em unidades funcionais ou institucionais - mais ameaçada se torna a existência social do indivíduo que dá expressão a impulsos e emoções espontâneas, e maior a vantagem social daqueles capazes de moderar suas paixões (idem).

Nesse ponto, é importante destacar que performances e produções de bandas e mesmo alguns comportamentos do público no espaço de consumo não devem ser tomados, sem cautela, sempre, como extensões ou fragmentos representativos dos comportamentos desses agentes em outros espaços, não marcados nem pela necessidade de espetacularização (como no caso dessa produção) nem de interesse situacional apenas ou sobretudo no divertimento, que é o caso do que ocorre, geralmente, no consumo. Pesquisadores que estudaram cenas análogas à do pagode aludiram também a esse ponto, sobre a autonomia e particularidade do espaço e circunstância do consumo (CECCHETTO, op. cit., p.111; SEMÁN e VILA, op. cit., p. 23; VIANNA, 1988, p. 110), o que vale também para a produção e sobre o que é produzido. Dito isso, podemos perceber também, entretanto, que a resposta do cantor demarca como a dança obscena, por exemplo, é um dos elementos expressos sem grande "moderação de paixão", de maneira mais "espontânea", pelas bandas que possuem um "horizonte menor", ou seja, que estão inseridas em redes de cadeias de ação mais curtas, o que, também, se relaciona com e expressa a 
posição que essas bandas ocupam na estrutura empresarial do campo. A partir do que é informado na entrevista, podemos interpretar como não sendo esse o caso da situação atual (2014) da banda Pagod'art, com trajetória mais longa e posições já conquistadas em relação às bandas mais novas, de sucesso mais explosivo, mas com permanência mais incerta:

Eu respeito a área de cada um que queira fazer isso, mas eu não pude me render a essa situação porque eu era cobrado por outras pessoas onde eu fui tocar. Já viajei, fui tocar na Europa, já toquei pelo Brasil todo. Eu sou um pai de família, não posso chegar com um CD que está em um nível que não seja de acordo com o meu perfil. A galera já conhece o meu perfil de música, então eu tenho que me preocupar muito com isso.

O que, através da reflexão de Elias, pode ser melhor compreendido quando o sociólogo argumenta que,

Geralmente, sob uma forte pressão social, membros dos estratos mais baixos acostumam-se a controlar suas emoções momentâneas e a disciplinar sua conduta com base em uma compreensão mais profunda da sociedade total e de sua posição nela. Por isso mesmo, seu comportamento é impelido cada vez mais na direção inicialmente limitada aos estratos superiores (idem, p. 209). 
Embora o Pagod'art, com suas canções cômicas sobre, por exemplo, os testículos avantajados de alguém ${ }^{15}$ (tema inusitado até mesmo para a produção do pagode...), em sua prática - diferentemente da situação de entrevista... - não seja o melhor exemplo de controle de conduta dentre as bandas do gênero (o Harmonia do Samba, melhor consolidado empresarialmente, é o modelo nesse sentido), a fala do cantor esboça uma conjuntura na qual algumas bandas miraram horizontes de mercado mais amplo, regendo-se pela "cultura de massa [que] tem, na sua procura de 'medianidade', uma espécie de mecânica moralidade pela qual recusa tudo o que é abnorme, preocupada, unicamente, em fixar-se sobre uma 'normalidade' que não incomode ninguém' (ECO, 2000, p. 312), enquanto outras, aprofundaram a " 'baixaria' que os próprios pagodeiros atribuem ao pagode" (LIMA, 2003, p. 212), e assim, nas palavras do cantor Flavinho, resignaram-se a "ficar em Salvador", o que, em verdade, é uma resignação a ser consumido apenas ou sobretudo pelo público juvenil e periférico que, a partir do que toda a conjuntura indica, se incomoda menos com (ou deseja mais) o traço de baixaria das produções.

Essas são algumas das linhas gerais das relações no âmbito da produção, que integram a cena musical na qual, em seus espaços de consumo, desenvolvi meu trabalho de campo, a partir do qual alguns pontos são abordados a seguir, enquadrados pela oposição mencionada na Introdução deste artigo.

${ }^{15}$ Ovão (Ovo de Avestruz) (autoria: Fábio - Franklin - Flávio - Jackson Junior):

https://www.youtube.com/watch?v=C8d5php3PBY.

Acesso: 25/04/2017. 


\section{Observação participante em espaços de consumo do pagode}

baiano

Nos itens abaixo apresento alguns pontos observados em dois tipos de espaço de consumo do pagode baiano. Em 3.1., trago fragmentos, estruturados em temas, do que foi observado em meu trabalho de campo mais sistemático, realizado nas noites dos finais de semana entre julho de 2014 e junho de 2015 em duas casas de show de pagode baiano, uma situada no bairro popular da Ribeira e outra no bairro de classe média da Pituba. Apesar da diferença social dos bairros, é muito baixa ou quase inexistente a diferença de público entre as duas casas. Nelas, observei que, em um amplo contingente de pessoas jovens, negras e mestiças em maioria quase que absoluta em relação aos poucos brancos, duas tendências de grupo, marcadas por vestuário, adereços, cortes de cabelo e outros traços, se distinguiam (em gradação, não como unidades exclusivas). Fazendo uma adaptação a esse contexto, então, utilizei a noção de fração de classe (BOURDIEU, 2008, p. 167) para categorizá-los em dois grupos, um que apresenta um estilo mais plenamente periférico (simplificadamente, me refiro como os mais pobres), majoritário nesses espaços, e outro mais próximo da classe média ou, possivelmente, com melhor acesso à educação formal e a atividades profissionais mais valorizadas, em relação à fração anterior, e com proporção um pouco menor no total dos frequentadores. Na parcela desses frequentadores que entrevistei, entre as duas frações, todos residem em bairros populares de Salvador. Não utilizei qualquer procedimento quantitativo que pudesse enquadrar economicamente os dois grupos que, à observação, se fizeram destacáveis em termos de fração de classe. A noção de hexis corporal (BOURDIEU, 2006'16,

${ }_{16}$ Ainda sem usar o termo hexis corporal, neste texto, originalmente publicado em 1962, as descrições que Bourdieu traz da corporeidade 
p. $86-87 ; 2008$, p. $165,318,439-440$ ) também foi utilizada, de maneira descritiva e integrada aos marcadores mencionados, para recortar as - de mais difícil apreensão - diferenças comportamentais gradualmente distribuídas entre os grupos. Em 3.2, sobre o espaço da praia, abordo o consumo do pagode entre famílias e os casos de acontecimentos mais extremos em uma festa de som automotivo, refletindo assim sobre a relação entre patamares de vergonha apresentados e frações de classe. A observação desse segundo espaço, concretamente, as praias da Boa-Viagem e da Ribeira, foi realizada de maneira mais incidental, desde 2010, período de elaboração de minha monografia de conclusão de curso de graduação, até o final da pesquisa de mestrado (2015), constituindo locais onde exerço meu próprio consumo cultural, visto que, de certa maneira, também sou nativo do universo que descrevo.

3.1. Fração de classe, convenções de gênero e o mais comum e o mais extremo nas performances do público em casas de show

A "resistência" ao avanço do patamar de vergonha, proposta neste artigo, encontra nas performances dançantes do pagode um eloquente meio de expressão. Elas abrangem desenvolvimentos coreográficos em direção ao prazer; "freios" e ultrapassagens nas convenções de gênero (sexual); e ainda recorrências, de um lado, mais amplas e "comuns", e do outro, mais raras e extremas, que podem servir de fonte de reflexão sobre possibilidades de mal-estar.

Um dos pontos que se destacou a mim, no trabalho de campo, foi um desses desenvolvimentos coreográficos em direção ao prazer. O antropólogo Ordep Serra - descrevendo

desenvolvida entre rapazes camponeses no Béarn contribuem bastante ao entendimento da noção. 
uma das maneiras das mulheres executarem o peneirado, no samba de roda, um passo que corresponde a uma posição sexual ${ }^{17}$ feminina na qual "a mulher se faz penetrar por um homem deitado ou inclinado, movendo-se sobre ele com movimentos que têm o pênis como eixo" (SERRA, 2009, p. 122) -, destaca que a mulher que dança "aproxima tanto quanto pode os quadris dos calcanhares, (...) [de modo que] a inclinação para trás a obrigará a abrir um tanto as pernas" (idem). Nas performances que observei entre o público feminino, por sua vez, essa etapa já estar embaixo - desse passo que, no pagode baiano, ficou conhecido como descer até embaixo (algo feito por mulheres e homens), ganhou um desenvolvimento - ao que parece, oriundo do funk carioca e chamado de machuca ou sequência do machuca -, no qual as jovens, já embaixo, de cócoras, dão algumas reboladas com os quadris e pélvis, simulando, justamente, estarem machucando um pênis que as penetrasse. Algumas desenvolvem essa rebolada em alternância, ora com os quadris inclinados para direita e ora com os quadris inclinados para a esquerda, simulando assim um empenho criativo (sexualmente) e prazeroso (para ambos) em sua ação de machucar. Esse é um passo bastante incisivo em sua representação de atos sexuais, quer sua performer tenha ou não qualquer intenção simulativa-representacional durante $o$ desempenho do passo. É um desenvolvimento recente, que certamente acompanha o desenvolvimento também recente do maior uso de tabuísmos nas letras de funk e pagode (o que reforça a dimensão sexual das letras). Sua performance é acompanhada, muitas vezes, de pantomimas como "linguinha para fora" e muitos risos e gargalhadas, em meio ao grupo de amigas que coreografam juntas. Observei esse passo sendo realizado por todos os grupos sociais das jovens frequentadoras

17 Essa posição sexual, na Bahia, recebeu o nome de coqueirinho, destaca o antropólogo (ibid.). 
de shows e, como observado por Spataro, sobre um outro contexto, embora "alguns textos das indústrias culturais efetivamente retomem 'clichês machistas' " é importante que quem reflete sobre esses fenômenos esteja aberto/a também à interpretação de que "esses textos sejam um disparador de fantasias, prazeres e jogos identitários diversos para muitas mulheres e, assim, um espaço de visibilização de mudanças - e, claro está, também de continuidades - das feminilidades contemporâneas" (SPATARO, 2013, p. 39).

O prazer buscado nas coreografias, muitas vezes, gera a oportunidade para a permanência ou a transposição das convenções de gênero (sexual). Nesse sentido, dentro de um grupo majoritário no público masculino, marcado por signos (vestuário, adereços, hexis corporal) que os põem, ao menos ao observador, como fração mais pobre no público - oposto a um grupo de proporção menor, cujos signos emitidos, por sua vez, os põem como mais próximos da classe média ou, ao menos, como com um acesso aos bens de consumo um pouco maior -, observei a presença de um pequeno subgrupo (disperso em turmas, não unificado) de rapazes que pouco ou nem sequer dançam, se mantendo, em grande parte do tempo, com a feição fechada, desafiante, mesmo durante as canções de refrões mais sexualizados ou mais ricos em instruções de passos de dança. A maior vergonha ou desinteresse pelo pagode mais sexualizado e divertidamente coreográfico, apresentada por esse pequeno subgrupo, talvez seja expressão de um tipo de masculinidade que rejeita o "um pouco de viadagem" que Lima identificou, através das palavras de seus informantes (op. cit., p. 212, 222 e 233), em sua etnografia da cena do pagode baiano, entre o final dos anos 90 e início dos anos 2000. Entretanto, é de se destacar que todos os grupos de rapazes observados em meu trabalho de campo (com exceção do subgrupo acima mencionado), mesmo quando dançam canções cujas letras dizem algo como "bota a mão em algum lugar e chacoalha o bumbum, bumbum, bumbum, 
bumbum...", endereçadas (na "narrativa" da letra) às mulheres, mas, na prática, feita para ser dançada por todos, mesmo nesse caso, dificilmente empinam a bunda como fazem as meninas e os rapazes homossexuais, embora o movimento feito por todos, na coreografia, seja quase que exatamente o mesmo, o que pode ser interpretado como expressão de um controle sobre as fronteiras entre a performance masculina heterossexual (e os elementos de virilidade que informam seu discurso subjetivizado e performado) e a performance que os fariam ser confundidos com os homossexuais. Os dançarinos de algumas das bandas mais recentes (Play Way, Pagodão), sobretudo quando mais jovens, por sua vez, avançam sobre essa fronteira de um modo que dificilmente qualquer homem heterossexual, no público, se arrisca. Alguns dos dançarinos chegam a fazer os quadradinhos de quatro e de oito, criados pelo grupo feminino de funk Bonde das Maravilhas, mas, como esse é um elemento excepcional em sua performance, cujo traço dominante é simular o macho lascador ${ }^{18}$, nem por isso deixam de ser vistos como gostosos, pelas meninas que passam boa parte do show na beira do palco, gritando seus nomes e tentando tocá-los (seja por real desejo sexual, seja apenas por brincadeira). Já as mulheres no público, por sua vez, têm menos ou nenhum pudor em fazer o gesto da metida - endereçado (na "narrativa" da letra) aos homens; mas, na prática, dançado por todos -, mas o fazem sem a incisividade muscular que os homens expressam com os braços e quadris (em gesto de penetração) e com

18 Lascador, miseravão, brocador, são palavras que circulam, comicamente, entre as classes populares soteropolitanas, para se referir, sobretudo, a um homem bem sucedido nas conquistas sexuais, além de em outros contextos, com usos conotados. Com a difusão midiática dos termos, frações das classes médias também os adotam, mas, muitas vezes, incluindo algum grau de distanciamento irônico na expressão. 
pantomimas de esforço e empenho (que, no imaginário dessas letras, expressam o sexo bem feito, que faz a mulher gozar...).

$\mathrm{Na}$ cena musical do pagode baiano, os jogos coreográficos entre transpor ou permanecer nas convenções de gênero (sexual) também dizem algo sobre certo grau de recalcitrância ou de adesão à interdição de alguns movimentos e da maneira de desempenhá-los; interdição essa estruturada tanto a partir de padrões de elegância mais ou menos difundidos e assentados entre os diferentes grupos sociais, como traços distintivos de "civilidade", quanto a partir das convenções mencionadas. Em ambos os casos, cada qual à sua maneira, a vergonha parece estar presente como agenciamento da interdição, e essa sua pluralidade de "aplicações" pode ser melhor observada no caso de um domínio no qual a estrutura de gênero já foi borrada, mas a diferença mais pertinente à fração de classe se expressa como hexis corporal na dança. Nesse sentido, nas casas de show que frequentei, as travestis estão quase sempre presentes, como proporção minoritária do público, e destacou-se para mim que, geralmente, quando com roupas mais caras (ou mais elegantes), dançavam de forma a não chamar tanto a atenção, em meio ao seu grupo de amigas (diferentemente dos rapazes homossexuais, nesse caso, predomina mais a companhia de outras travestis; embora, às vezes, formassem um subgrupo de uma turma maior, composta também por meninas e rapazes heterossexuais). Por outro lado, quando com roupas mais baratas - e, muitas vezes, com o corpo ainda não tendo atingido o ápice do processo de feminilização, através das cirurgias e aplicações de silicone (etapa geralmente já atingida pelo grupo acima mencionado) -, muitas vezes, faziam danças mais ostensivas, como empinando a bunda entre as barras que formam o parapeito do camarote, de modo a chamar muito a atenção de quem se encontrava embaixo, na pista. 
É importante destacar que a grande maioria das pessoas que compõe o público está ali apenas para dançar, seja de maneira individual, em meio ao seu grupo de amigos, sem chamar muito a atenção dos circundantes, seja na modalidade que parece ser a mais prazerosa exercitada ali, que é a coreografia em conjunto (de 3, 5, 8 ou mais pessoas; nem sempre sendo todas conhecidas; podendo, quem queira e tenha competência, nela se integrar), na qual o prazer da sincronização dos movimentos é propriamente estético, pois diz respeito à fruição que esses dançantes mantêm das formas que seus corpos vão elaborando, mas é um prazer advindo também de sua ação performática e lúdica. A excitação proporcionada a cada pessoa que dança, nessa segunda modalidade, é maximizada pelo desafio de acompanhar o grupo ser feito em público, com o grupo de dançantes roubando a atenção daqueles que estão à sua volta, admirando-os. Trata-se de um caso de criatividade posta em ação pelo público e em meio ao público, com seus resultados muitas vezes sendo absorvidos pelos dançarinos das bandas. E é o exercício também de uma autocontemplação ativa, móvel, em conjunto e que não necessita banir o imaginário da sexualidade, muito pelo contrário, dele se alimenta e toma-o como base para fantasiar.

Algumas vezes, entretanto, vi grupos de rapazes e meninas, cujas roupas, adereços e toda a hexis corporal indicam fazerem parte das frações mais pobres (e majoritárias) dos frequentadores, fazendo coreografias muito ostensivas sexualmente, em que as meninas com as mãos e os pés no chão, de quatro, mas agachadas, empinando a bunda, tinham essa parte do corpo golpeada pelo pênis (pela pélvis, na verdade) dos rapazes que, atrás delas, se agachavam com pernas abertas na frente e, com coluna em arco, um dos braços se apoiando no chão, atrás, e o outro suspenso no ar, em baixa altura. Essa performance, feita, das vezes que vi, sempre em áreas próximas ao palco, chamam muito a atenção da maioria das pessoas que 
estão ali dançando, aglomeradas (embora a performance só seja possível quando há algum espaço em meio à multidão). São feitas realmente para chamar a atenção. E são raras. Acho que as vi sendo feitas apenas duas ou três vezes, ao longo de mais de um ano de idas constantes aos shows. Dentro do que observei, esse tipo de performance dificilmente é feito por pessoas que - sobretudo no caso das meninas -, pelo vestuário e outros signos, pareçam integrar as frações do público mais próximas da classe média. A performance é considerada, amplamente dentro do público do pagode, e talvez mesmo por seus protagonistas, como algo bem baixo-astral (o que nem sempre é igual a negativo), o que é indicativo de como o patamar de vergonha se expressa, variavelmente, no grupo social que dá base a esta cena musical, e põe como problema científico a complexa identificação de como a fração de classe, nas classes populares que compõem quase a totalidade dos frequentadores dos shows, exerce efeito como clivagem entre tendências a desempenhar ou a não desempenhar essas performances. No item seguinte, nesse sentido, buscarei apresentar como o fator geração também é relevante para a reflexão sobre esse tipo de caso.

Para finalizar esse item, é importante destacar que o espaço de consumo do pagode fica muito marcado, com a difusão na internet, de imagens gravadas com celular por pessoas dentre o próprio público, pelo que ocorre de mais extremo na festa, seja no caso das performances como a acima mencionada, seja nas performances que ocorrem em cima do palco, ou ainda no caso das brigas. Essa difusão acaba contribuindo para certo mal-estar que pode ser captado $^{19}$ na

${ }^{19}$ Durante o trabalho de campo, desenvolvi também entrevistas com frequentadores/ras das casas de shows, além de monitoramento das redes sociais (facebook) de grupos de consumidores e produtores do 
maneira como o público do gênero - parcelas dele, ao menos recebe as críticas e estigmatizações elaboradas sobre seu item de consumo cultural por detratores do gênero musical e das práticas que associam a ele. Nunca é demais ressaltar, entretanto, que a grande maioria das pessoas simplesmente dança de forma a não buscar chamar muito a atenção de quem está em volta, dança para si e em interação com seu grupo de amigos (visto que é ínfima a quantidade de pessoas que vão sozinhas a esses shows. Praticamente nula).

3.2. Sociabilidade familiar, faixa etária, fração de classe e o mais extremo no espaço da praia

Um dos espaços que mais proporcionam acesso à observação de como patamares de vergonha específicos dos grupos sociais que consomem o pagode se apresentam são as praias populares de Salvador. Seus frequentadores, evidentemente, permanecem a maior parte do tempo sentados nas cadeiras de plástico, com mesa, tomando muitas cervejas, em grupo, ou em cangas, estiradas na areia. Dessa forma, quando ocorrem, as respostas corporais que eles dão ao pagode veiculado pelas barracas são: o canto, geralmente sem grande concentração, de apenas alguns trechos da canção; batuques esparsos e feitos sem grande concentração, na mesa com as mãos ou na areia com os pés. Vez ou outra, em menor proporção, algum homem ou mulher (em qualquer faixa etária), que esteja em pé, faz, de maneira pouco enfática e sem grande concentração, movimentos de dança que são uma versão contida da dança de base do pagode, com os pés plantados ao chão, sem movê-los, com micro flexões de joelho, micro volteios de ombro na vertical (em alternância contínua de movimento, de um ombro para o outro) e quadril em leve movimentação para frente e para trás, tudo isso, em simultâneo. A pessoa

gênero (de maneira sistemática, entre 2013 e 2015), e esse aspecto foi observado. Pode ser conferido em CHAGAS, 2015b, p.161-187. 
muitas vezes está conversando com outra, sem sequer cantar a letra da canção, mas mantém simultaneamente essa microdança não muito consciente nem muito intencional. Essas são as respostas corporais mais recorrentes entre o público, na praia, que gosta do pagode.

Acontece que, em casos bem mais raros, entretanto, algumas pessoas, jovens ou adolescentes, mas talvez sobretudo adultos e, em menor proporção, mas sem ser caso incomum, pessoas já por volta dos 50 anos ou mais (ou seja, pessoas que não cresceram consumindo a produção do gênero musical em questão, que não estruturaram seu gosto a partir dele), elaboram jocosas brincadeiras a partir da dança do pagode, como que para provocar $^{20}$ algum/ma dos/das seus/suas companheiros/ras de mesa. Nesses casos, a "essência" de baixaria $^{21}$ do pagode se revela. Vemos mulheres que dançam empinando a bunda na direção do rosto (estando a pessoa sentada) ou do tronco de algum/ma de seus/suas companheiros/ras de mesa, seja o namorado, a filha, alguma amiga, a mãe, etc. (ao que a pessoa sentada, geralmente mulher, pode responder dando um tapa na bunda e dizendo: "sai!", ou algo do tipo, em meio aos risos e gargalhadas). Vemos homens que agarram outros por trás e fazem gestos, dançando, de penetração, aos risos, tentando constranger o segurado diante do grupo. Vemos também mulheres que, sentadas, com a base

${ }^{20}$ Bourdieu, em breve descrição do bar popular, em oposição ao restaurante burguês, também ressaltou, nas práticas desenvolvidas no primeiro, "a arte de zombar dos outros sem irritá-los por meio de deboches ou de injúrias rituais que são neutralizados por seu próprio excesso" (2008, p. 173).

${ }^{21}$ Apesar de esse termo ter uso amplamente difundido no Brasil, na comunidade em questão ele ganha singularidade pela possibilidade de ser usado com conotação positiva, com base em características de transgressão cômica e prazerosa. Outro termo análogo e que carrega a mesma ambivalência é o adjetivo baixo-astral. 
da cadeira de plástico encostada à frente do tronco, fazem gestos, dançando, de cópula, com vai-e-vem dos quadris e nádegas, juntamente com pantomimas voltadas para as amigas e amigos, com linguinha para fora, olhos revirando simulando gozo sexual, etc.

Em todos esses casos, as letras mais "baixas" são as que melhor propiciam esses comportamentos que desenham nas faces das pessoas alegres expressões e as fazem dar muitas gargalhadas. Uma letra que diga algo como, por exemplo, " $a$ piriguete anda com um fio só, tooooodo enfiado" pode ser atribuída, às gargalhadas, por uma mulher a outra, e são esses usos que, por exemplo, os grupos de classe média letrada com recepção mais antipática ao pagode muitas vezes desconhecem, têm dificuldade em entender, aceitar e, sobretudo, dificuldade em fruir seus prazeres; prazeres esses buscados por quem vai à praia não em busca de silêncio e tranquilidade...

Todas essas práticas acima mencionadas, as mais comuns e as mais raras, são familiares, ou seja, não são desenvolvidas nem apenas, nem sequer sobretudo, por adolescentes e jovens na ausência dos pais (como predomina nos shows de e eventos com pagode). No mesmo espaço da praia - mais precisamente, em uma festa de som automotivo ${ }^{22}$ recorrentemente ocorrida nas tarde e noites dos finais de

${ }^{22} \mathrm{O}$ jovem Daniel do Paredão, produtor de festas que recebem o nome de Paredão, informa que estas ocorrem em local fechado, com cobrança de ingresso, no qual é instalado uma carrocinha, ou paredão, uma placa formada por várias caixas de som de grande amplitude. Quando o "evento" ocorre em lugar aberto, como uma praça ou a pista do caso que descrevo, formado simplesmente pela reunião de pessoas e alguns carros cujos aparelhos de som dos porta-malas as animam, trata-se apenas de uma festa de som automotivo. Informação dada no evento acadêmico Quebrando Tudo 2, organizado pelo Grupo de Pesquisa Corpo e Política (Universidade Federal do Recôncavo da Bahia), realizado em 09/07/2015, Cachoeira, Bahia. 
semana dos verões de 2010 a 2014, na pista que margeia a praia da Boa-Viagem -, entretanto, pude observar alguns acontecimentos nos quais os matizes do patamar de vergonha dos frequentadores se tornam mais visíveis.

Em um deles, ocorrido em vários fins de semana entre 2013 e 2014, as performances dançantes que um grupo de meninas e de meninos aparentemente homossexuais, adolescentes e pré-adolescentes, faziam no meio da pista, chamavam bastante a atenção dos outros frequentadores do evento, cuja faixa etária era mais próxima ou já na fase adulta, e que se margeavam nas duas calçadas da pista, dançando apenas para si. No período em que frequentei e observei esse encontro espontâneo, não organizado, se difundiu em Salvador o funk do grupo Bonde das Maravilhas, em versão putaria (que se opõe às versões light para divulgação em TV e rádio) e, junto com sucessos do cantor de pagofunk Robyssão e de outros grupos de pagode, os passos do quadradinho de quatro, quadradinho de oito, passinho do espaghetti e outros chamavam a atenção dos presentes por apresentarem uma carga sexual performática mais forte do que o de costume no pagode baiano e, me parece, no funk carioca de até então, além do próprio vestuário das meninas, micro-shorts muitas vezes de lycra ou algum outro tecido sintético, justíssimos, tudo isso conjugado à sua faixa etária mais próxima à infância. Certo grau de embaraço era expresso, sobretudo, pelas jovens mais próximas da fase adulta, que faziam exclamações entre si, como: “Ó pra isso, menina!" ou "Que baixaria, viu!", em um misto de espanto e comicidade, geralmente sem, mas às vezes com algum grau de desaprovação, além de comentários mais gerais sobre as meninas serem mal-cuidadas pelas mães...

Em outro ocorrido, dessa vez isolado (ao menos, em minha presença), uma jovem-adulta, embriagada, trajando biquíni por baixo de uma saída-de-praia improvisada com uma canga, dançando uma coreografia que pedia para "colocar as 
mãozinhas no chão, e jogar o bumbum pro alto!", teve parte de sua vagina posta à mostra por conta da brusquidão com que fez o movimento. Sem se constranger com o fato, a jovem manteve a posição, enquanto dançava, e seu grupo de amigos e amigas, então, em meio a gargalhadas e brincadeiras, fez uma redoma à sua volta, para impedir - de maneira jocosa, entretanto - que as pessoas que se aglomeravam próximo (eu incluso) vissem a exibição. Um dos amigos da jovem, também adulto e consumindo bebida alcoólica - como a grande maioria dos presentes no evento -, entretanto, teve a idéia de cobrar cervejas ao aglomerado de pessoas para que ele e o grupo de amigos/as abrissem a redoma e, assim, todos pudessem ver a exibição da jovem, o que ocorreu por mais duas vezes, com a mesma puxando o biquíni para o lado, e mostrando totalmente a vagina, enquanto algum homem ou rapaz dava alguma latinha de cerveja ao grupo. Estando o grupo de amigos já parcialmente embriagados, certamente a finalidade do jogo era muito mais a diversão do que, simplesmente, a aquisição de cervejas. Após essas duas "rodadas", quando algumas pessoas começaram a tentar gravar a cena com seus aparelhos celulares, o grupo protagonista pediu mais energicamente - mas mantendo os risos - que a jovem embriagada findasse a exibição. A desaglomeração de pessoas deixou no ar uma dispersão de frases como: "Você viu?! Que bai-xa-ria, viu, menina! (com um acento na palavra baixaria, dando-lhe ênfase)", dita pelas mulheres, ou, dita pelos rapazes: "Rapaz, é puta mesmo, viu?!", tudo isso em meio a risos que enredam a parcial desaprovação moral em um prazer de espectador.

Nesse espaço praieiro da festa de som automotivo, o vestuário e os adereços utilizados, bem como a hexis corporal, indicam uma homogeneidade social maior entre os frequentadores, se comparado com as casas de show. Mesmo assim, entretanto, algumas das diferenças, principalmente para o caso dos rapazes (tipos de bonés utilizados, tipos de corte de 
cabelo, uso ou não do batidão - uma corrente pesada, de prata ou de latão -, roupas de camelô ou de loja de departamento, etc.), permitem ao observador ambientado inferir - certamente, com alguma margem de erro -, a maior proximidade dos presentes a um estilo de vida (certamente, com bases socioeconômicas, o habitus fazendo a mediação) mais periférico/favelado ou com maior acesso aos conteúdos das classes médias. E dessa forma, portanto, é relevante destacar aqui que a marca da fração de classe, mais uma vez, foi perceptível, com os dois comportamentos mais extremos descritos acima se concentrando nas parcelas que, aparentemente, são mais pobres, ou, para expressar em termos mais precisos - visto que essa parcela é majoritária nos espaços de consumo do pagode e os comportamentos mais "comuns" também, em sua maioria, são apresentados por ela - foi perceptível, em meu trabalho de campo, que comportamentos como esses, mais extremos, aparecem em uma frequência muito menor nos grupos que aparentam estar mais próximos da classe média. Embora haja maior afinidade estilística dos comportamentos dessa fração mais pobre - ao menos, nos espaços que observei - com esses atos mais extremos (em relação à outra fração), os mesmos aparecem aí ainda de maneira excepcional, e ainda resta muito a entender sobre por que, vivendo nos mesmos condicionamentos sociais (e guardando em suas corporeidades uma memória étnica em comum), apenas alguns indivíduos produzem um resultado tão singular enquanto uma maioria não.

Se abstrairmos um pouco o problema mais complexo de por que apenas alguns, e não todos ou muitos dos "membros" dessa fração mais pobre desempenham esses atos, e nos focarmos na comparação, em por que não (ou apenas em medida bem menor) aparecem nas frações mais próximas das classes médias, encontramos uma explicação em palavras mais cruas de Norbert Elias: 
A construção do superego de acordo com modelos da classe superior gera também, na classe em ascensão, uma forma específica de vergonha e embaraço, mas que é muito diferente das sensibilidades de grupos inferiores que não têm probabilidade de ascensão individual. $\mathrm{O}$ comportamento deles pode ser mais tosco, mas (...) vivem mais vigorosamente em seu próprio mundo, sem qualquer reivindicação ao prestígio da classe superior e, por conseguinte, com maior liberdade para liberar paixões (1993, p. 258).

No que diz respeito ao estudo da cena musical do pagode baiano, que é um exemplar de uma ampla cultura periférica, não restrita à realidade nacional, como mencionado na Introdução deste artigo, é importante refletir sobre comportamentos mais extremos, como os acima mencionados, porque, embora excepcionais, eles são fonte de proporção considerável do que há de mal-estar captável em agentes, na produção e no consumo, que vivenciam e dinamizam esse universo (muito embora, pareça haver corte de fração de classe e de faixa etária aí também). Enquanto performances dançantes e brincadeiras em espaços de consumo musical, apenas um etnocêntrico moralismo puritano seria capaz de condená-las. Se fazem parte de uma estrutura mais ampla de comportamento, entretanto, podem ser índices de problemas mais amplos e de limitações sociais aos seus agentes.

Tratando-se de consumo cultural aqui, o recorte de meu trabalho de campo com foco na observação de espaços de shows, encontros e eventos não permite penetrar muito na cotidianidade "extra-musical" dos agentes observados, por exemplo, nas apropriações que elaborem, das produções do 
gênero musical em questão, a outros âmbitos, domínios e contextos de seus processos de formação de identidade e subjetividade, este trabalho tendo como limite da sua contribuição, no que diz respeito ao tema dos possíveis problemas associados a esse consumo, a localização dos comportamentos mais extremos entre membros/subgrupos nas frações mais pobres, sem que se possa generalizar nessa fração a apresentação desses comportamentos, visto que, nelas também, eles são excepcionais, mas, ainda assim, aparecendo numa proporção maior do que nas frações mais próximas das classes médias, até onde minha percepção foi capaz de alcançar.

\section{Conclusão}

O pagode baiano é consumido em uma série de diferentes espaços em Salvador e em diversas modalidades também, seja através de usos mais intencionais e conscientes (como no caso da presença em um show, como trilha em uma festa de aniversário, etc.), seja através de usos intercalados ao desenvolvimento de outras atividades (como entre vendedores em lojas de eletrodomésticos, como suporte coreográfico para trabalho aeróbico em academias de ginástica, ou ainda como trilha para a espera da condução em pontos de ônibus). Se, às vezes, o embaraço que suas produções causam em seus detratores se deve não apenas aos termos baixos ${ }^{23}$ utilizados em

${ }^{23}$ Sem negar a potência, contemporânea inclusive, do "controle do carnavalesco nas classes médias" (STALLYBRASS E WHITE, 1986, p. 171-190; FEATHERSTONE, 1995, p. 113-117), a interpretação de que a antipatia às produções de cenas musicais como a do pagode baiano resulta, apenas, de um puritanismo de classe média, ao meu ver, tem algo de limitada, não dando conta de alguns dos conteúdos dos processos de informalização dos comportamentos e emancipação das emoções, pelas quais essa classe (e não apenas ela) passou no Século XX, informados, parcialmente, pela "proletarialização da burguesia" 
(algumas de) suas letras, mas também ao que é considerado, por esses agentes, como "pobreza" poética das mesmas, uma das riquezas deste fenômeno, ao meu ver, se encontra na pluralidade de "aplicações" que um grande contingente populacional na cidade tem dado, há mais de 20 anos, a essa produção, tornando-a pervasiva à sua cotidianidade. Portanto, também à elaboração de seus processos de identidade e subjetividade, no que, considero, cabe a quem se debruça intelectualmente sobre o fenômeno estar atento (e aberto...) tanto às potencialidades (as mais diversas) quanto às limitações que o mesmo possa proporcionar - ou reforçar - ao seu grupo social de consumo e produção. Foi nesse sentido que a oposição entre resistência - a um patamar de vergonha que não corresponde às práticas observadas na cena musical e a um considerável número de outras práticas do grupo social em questão - e mal-estar foi trabalhada neste artigo.

Tentei demonstrar que há um padrão de vergonha (e embaraço) específico ao grupo social que dá base ao público do pagode baiano, aberto a prazeres que lhes são muito caros, mas que apresenta variações, relacionadas, em algum grau, com a diversidade de condicionamentos sociais que configuram, nele, diferentes frações. Não ignoro os riscos de estigmatização das frações mais empobrecidas a partir do que é expresso aqui, mas acredito que indícios devem ser escrutinados e, após serem refutados ou confirmados, que a reflexão traga alguma contribuição à ação política, inclusive, se isso for o indicado, com a localização com mais propriedade, com mais precisão, do problema na estrutura que lhe conforma.

(WOUTERS, 2012, p. 551) decorrente da maior interpenetração entre as diferentes classes sociais (idem, p. 557-558). Suponho, entretanto, que esses processos não ocorrem igualmente entre as diferentes frações de classe média, sobretudo, levando-se em consideração as diferenças de centralidade do capital ou cultural ou econômico, em suas respectivas reproduções, como enquadra Bourdieu (2008). 
Algumas potencialidades do fenômeno, entretanto, me parecem já evidentes e efetivas, seja como signo de uma reconquista, por meio do gozo corporal, de um corpo outrora possuído por outro (PINHO, 2015, p. 234), seja como o reforço que realiza do humor com que o grupo social em questão carrega algumas de suas outras práticas, o que parece lhes ser tão caro.

\section{Referencias bibliográficas}

ACOSTA, Leonardo. La timba y sus antecedentes en la musica bailable cubana. Salsa Cubana, nº 6, p. 9-11, 1999. Disponível em:

http://www.proyectosalonhogar.com/Enciclopedia Ilustrada/Le onardo Acosta.htm. Acesso: 23/04/2017.

BAUMAN, Zygmunt. O Mal-Estar da Pós-Modernidade. Rio de Janeiro: Jorge Zahar, 1998.

BOURDIEU, Pierre. O camponês e seu corpo. Revista de Sociologia e Política, no 26, p. 83-92. Junho, 2006. Disponível em: http://revistas.ufpr.br/rsp/article/view/8106/5723 Acesso: 23/04/2017.

A Distinção: crítica social do julgamento. Porto Alegre: Editora Zouk/São Paulo: EDUSP, 2008.

CHAGAS, Ledson. O corpo erótico-dançante como matriz cultural de algumas cenas musicais juvenis periféricas contemporâneas. In: Anais do XIV Congresso IberoAmericano de Comunicação IBERCOM: Comunicação, Cultura e Mídias Sociais, p. 1759-1768, 2015a, São Paulo, SP. Disponível em: http://www3.eca.usp.br/biblioteca/publicacoes/e-book/anais-doxiv-congresso-ibero-americano-de-comunica-o-ibercom-2015. Acesso: 23/04/2017. 
Corpo, dança e letras: um estudo sobre a cena

musical do pagode baiano e suas mediações, Dissertação de Mestrado apresentada ao Programa Multidisciplinar de PósGraduação em Cultura e Sociedade da Universidade Federal de Bahia/UFBA, 2015b.

CECCHETTO, Fátima Regina. Violência e estilos de masculinidade. Rio de Janeiro: Editora FGV, 2004.

ECO, Umberto. A canção de consumo. In: ECO, Umberto. Apocalípticos e Integrados. $5^{\underline{a}}$ ed., Tradução: Pérola de Carvalho. São Paulo: Perspectiva, 2000.

ELIAS, Norbert. O Processo Civilizador. Volume 2: Formação do Estado e Civilização. Rio de Janeiro: Jorge Zahar, 1993.

O Processo Civilizador. Volume 1: Uma

História dos Costumes. $2^{\mathrm{a}}$ ed., Rio de Janeiro: Jorge Zahar, 2011.

FEATHERSTONE, Mike. Cultura de consumo e pósmodernismo. São Paulo: Studio Nobel, 1995.

FONTANELLA, Fernando Israel. A Estética do Brega: Cultura de Consumo e o Corpo nas Periferias do Recife. Dissertação de Mestrado apresentada ao Programa de Pós-Graduação em Comunicação da Universidade Federal de Pernambuco/UFPE, 2005.

GILROY, Paul. O Atlântico Negro: modernidade e dupla consciência. Tradução: Cid Knipel Moreira. Rio de Janeiro: Editora 34/Universidade Cândido Mendes-Centro de Estudos Afro-Asiáticos, 2001.

JANOTTI JR, Jeder. Por uma análise midiática da música popular massiva. Uma proposição metodológica para a compreensão do entorno comunicacional, das condições de produção e reconhecimento dos gêneros musicais. E-compós, v.1, $\mathrm{n}^{\mathrm{o}}$ 6, p.1-15, Agosto, 2006. Disponível em: http://compos.org.br/seer/index.php/ecompos/article/viewFile/84/84 Acesso: 23/04/2017. 
. Entrevista - Will Straw e a importância da ideia de cenas musicais nos estudos de música e comunicação. E-Compós, v.15, no 2, p. 1-10, Maio/Agosto, 2012. Disponível em: $\quad$ http://www.compos.org.br/seer/index.php/ecompos/article/view/812. Acesso: 23/04/2017.

LEME, Mônica Neves. Que Tchan é Esse? Indústria Cultural e Produção Musical no Brasil dos Anos 90. São Paulo: Annablume, 2003.

LIMA, Ari. A Experiência do Samba na Bahia. Práticas corporais, raça e masculinidade. Tese de doutorado apresentada ao Programa de Pós-Graduação em Antropologia Social da Universidade de Brasília/UnB, 2003.

LOPES, Maria Immacolata Vassalo de; BORELLI, Sílvia Helena Simões; RESENDE, Vera da Rocha. Vivendo com a Telenovela: mediações, recepção, teleficcionalidade. São Paulo: Summus Editorial, 2002.

LOPEZ CANO, Ruben. Del barrio a la academia. Introducción al dossier sobre timba cubana. Trans. Revista Transcultural de Música, $\mathrm{n}^{\mathrm{o}}$ 9, dezembro, s/p, 2005. Sociedad de Etnomusicología. Barcelona, Espanha. Disponível em: http://www.sibetrans.com/trans/articulo/165/del-barrio-a-laacademia-introduccion-al-dossier-sobre-timba-cubana Acesso: 23/04/2017.

(2007). El chico duro de la Habana. Agresividad, desafío y cinismo en la timba cubana. Latin American Music Review/Revista de Música Latinoamericana, v. $28, \mathrm{n}^{\mathrm{o}} 1$ 1, p. 24-67, 2007. Disponível em: https://muse.jhu.edu/article/217078/pdf Acesso: 23/04/2017.

MARTÍN-BARBERO, Jesús. Dos meios às mediações: comunicação, cultura e hegemonia. 5a ed., Rio de Janeiro: Editora UFRJ, 2008.

MATTOS, Carla. No ritmo neurótico: cultura funk e performances 'proibídas' em contexto de violência no Rio de Janeiro. Dissertação de Mestrado apresentada ao Programa de 
Pós-Graduação em Ciências Sociais da Universidade do Estado do Rio de Janeiro/UERJ, 2006.

OLIVEIRA, Sirleide. O pagode em Salvador: produção e consumo nos anos noventa. Dissertação de Mestrado apresentada ao Programa de Pós-Graduação em Ciências Sociais da Universidade Federal da Bahia/UFBA, 2001.

PINHO, Osmundo. O Fantasma do Estado: Genocídio e Necropolítica. Reaja nas Ruas (blog), 2014. Disponível em: http://reajanasruas.blogspot.com.br/2014/07/o-fantasma-doestado-genocidio-e.html. Acesso: 23/04/2017.

"Putaria": Masculinidade, negritude e desejo no pagode baiano. Maguaré, v. 29, no 2, p. 209-238, 2015. Universidad Nacional de Colombia. Disponível em: http://www.revistas.unal.edu.co/index.php/maguare/article/vie w/61671/58092 Acesso: 23/04/2017.

PLATÃO. A República. Tradução: Enrico Corvisieri. São Paulo: Editora Nova Cultural, 1997.

RODRIGUES, Fernando de Jesus. Economia Simbólica da Excitação: sobre os circuitos musicais populares nas periferias e o sentido erótico-dançante no tecnobrega e no pagode baiano. Tese de Doutorado apresentada ao Departamento de Sociologia da Universidade de Brasília/UnB, 2011.

Aspectos da estrutura de poder

entre homens e mulheres e as diversões erótico-dançantes no Brasil contemporâneo. In: Anais do XIV Simpósio Internacional Processos Civilizadores: civilidade, fronteira, diversidade, p.1-15, 2012, Dourados, MS. Disponível em: http://www.uel.br/grupo-

estudo/processoscivilizadores/portugues/sitesanais/anais14/arq uivos/textos/Workshop/Trabalhos Completos/Fernando Rodri gues.pdf Acesso: 23/04/2017.

SANZ GIRALDO, María Alejandra. Funk Carioca e Champeta Cartageneira: Corporalidades, Trangressões e Negociações em músicas e bailes de periferia. Dissertação de Mestrado 
apresentada ao Programa de Pós-Graduação do Departamento de Antropologia do Instituto de Filosofia e Ciências Humanas da Universidade Federal do Rio Grande do Sul/UFRGS, 2014.

SEMÁN, Pablo. Cumbia villera: avatares y controversias de lo popular realmente existente. Nueva Sociedad, no 242, p. 149161, 2012. Disponível em: http://historiapolitica.com/datos/biblioteca/musica\%20y\%20poli tica_seman.pdf Acesso: 23/04/2017.

SEMÁN, Pablo e VILA, Pablo. Cumbia villera: una narrativa de mujeres activadas. Colección Monografías, $\mathrm{n}^{\mathrm{o}}$ 44, Caracas: Programa Cultura, Comunicación y Transformaciones Sociales, CIPOST, FaCES, Universidad Central de Venezuela, 2007. Disponível em: http://www.elortiba.org/pdf/cumbia villera7.pdf $\quad$ Acesso: 23/04/2017.

SERRA, Ordep. Rumores de festa. O sagrado e o profano na Bahia. Salvador: Editora EDUFBA, 2009.

SPATARO, Carolina. Las tontas culturales: consumo musical y paradojas del feminismo. Revista Punto Género, nº 3, 2013. Disponível em: http://www.revistapuntogenero.uchile.cl/index.php/RPG/article LviewArticle/30265. Acesso: 23/04/2017.

STALLYBRASS, Peter e WHITE, Allon. The politics and poetics of transgression. New York: Cornell University Press, 1986.

STRAW, Will. Scenes and Sensibilities. Public, no 22/23, p. 245257, 2002. Disponível em: http://public.journals.yorku.ca/index.php/public/article/view/30 335/27864 Acesso: 23/04/2017.

TATIT, Luiz. O século da canção. $2^{a}$ ed., Cotia: Ateliê Editorial, 2008.

TINHORÃO, José Ramos. História Social da Música Popular Brasileira. São Paulo: Editora 34, 1998. 
. Os sons dos negros no Brasil. cantos, danças, folguedos: origens. 2aㅡ ed., São Paulo: Editora 34, 2008. VIANNA, Hermano. O mundo funk carioca. Rio de Janeiro: Jorge Zahar, 1988.

VICENTE, Eduardo. Segmentação e Consumo: a produção fonográfica brasileira. Revista ArtCultura. Uberlândia: EDUFU, v. 10, n. 16, p. 99-117, jan./jun., 2008. Disponível em: http://sociologia.fflch.usp.br/sites/sociologia.fflch.usp.br/files/E Vicente.pdf. Acesso: 23/04/2017.

WOUTERS, Cas. Como continuaram os processos civilizadores: rumo a uma informalização dos comportamentos e a uma personalidade de terceira natureza (Tradução: Thamires Castelar e Bruno Gontyjo). Sociedade e Estado, v. 27, no 3, set/dez 2012. Disponível em: http://www.scielo.br/pdf/se/v27n3/06.pdf. Acesso: 23/04/2017.

Enviado em: 29/04/2017

Aceito em: 10/07/2017 